\title{
A proposed Conception to Develop the Professional Competencies of the Shadow Teacher According to the Techniques of The TEACCH program
}

\author{
Aya Mohamed Erashidy \\ Faculty of Education, Tanta University, Egy pt \\ ay aelrashidy85@gmail.com
}

\begin{abstract}
The aim of the cument research is to develop a Suggested concept that contributes to developing the professional competence of the shadow teacher, the research topic derives its importance from the importance of the shadow teacher in the educational integration process. As approved by Ministerial Resolution No. (42) Of 2015 and despite its importance, its preparation and development was neglected, from here came the research problem, which is represented in: Lack of interest in preparing the shadow teacher appropriate preparation in parallel with the tasks assigned to him The lack of programs to develop the professional aspects of the shadow teacher, The lack of specific shape form of the professional competencies that must be available in the shadow teacher. The results of the research explain the professional competencies of the shadow teacher and how to develop them through the use of therapeutic and educational techniques for one of the most famous and most effective treatment programs, which is the TEACCHO program.
\end{abstract}

Keywords: Shadow Teacher - TEACCH Program-Professional Competences

\section{Introduction}

There is no doubt that the integration of children with special needs into the inclusive educational system has become a priority, provided that appropriate intervention and support are available. For inclusion to be successful, children must participate in all or most school activities. Sometimes there is a need for additional help or additional support for these children so that they can benefit from inclusion, and here the "shadow teacher" can provide this additional support so that the child can attend the regular classroom, Therefore, the development of shadow teacher preparation programs has become necessary to bring about the desired development in the inclusive educational system, and therefore the state has tended to issue laws that guarantee the rights of these children with special needs. One of the most important decisions issued against these children is Ministerial Resolution No. 42 of 2015. Where he stressed the need for educational assistance /teachers The Shadow Teacher remained with some cases that the school would allow its admission into the general educational system Depending on the degree of disability.
The ministerial decision also emphasized the importance of the shadow teacher and his effective role in the educational integration process.

So, the shadow teacher is the product of educational changes in the field of education and care for children with special needs, because of its positive impact on the success of the educational integration process, as proven by many studies such as the study of (Manasala, 2009), (Sevien, 2007), (Kamath, 2016). (Melanie.2015), (Mohammed, 2012),( Irawan, 2015) and (Awad, 2016) and other studies that emphasized the important role played by the shadow teacher and stressed the importance of preparing him and paying attention to his training to ensure the success of the educational integration process for children with disabilities and Special needs in general education schools.

\section{The Shadow Teacher}

The shadow teacher is considered an educational assistant who works directly with one child with special needs during the kindergarten and primary school years, and provides him with the ass istance he needs within the 
framework of an additional assistance format. (manasala\& Dizon,2009).

The shadow teacher is referred to as a skilled teacher who works alongside the teacher in the same class to provide the necessary academic, social, behavioral, and emotional support to the child with special needs who is in the classroom for whom the shadow teacher is responsible. (kamath, 2016).

The main tasks that distinguish the shadow teacher from other teachers of students with special needs

- He works all the time with only one child.

- He does not leave the child throughout the school day, and may be stay with him can extend beyond the school day at home.

- The family responsible for providing the shadow teacher. (yuwono,2017)

The role of the shadow teacher

The (ELKARAAN, 2017) study confirmed that the role of the shadow teacher is to provide support to the student, the teacher, and the school, and confirmed that the instructions issued by him should be easy and clears to the teacher's instructions not to replace them

In other words, the role of the shadow teacher is to simplify the information issued by the classroom teacher so that the child can understand it, that is, the shadow teacher is the link between the student and the teacher and a transmitter and mediator of knowledge within the regular classroom, with an emphas is that the more complex and severe the needs of the students, the less the communication provided by the main teacher $\mathrm{W}$ ith these students the support of the shadow teacher increased. (Devecchi,2012).

From this point, Lestari (2019) study confirmed that working as a shadow teacher with children with special needs who suffer from intellectual disability, behavioral and emotional disorders, and leaming disorders, is a stressful task because shadow teachers must be able to ensure that the child is always adaptive During the lesson, the shadow teacher must realize how to bring the child to a high degree of adaptation, and it is natural that this task takes a lot of time.

A study (Mahrus, 2019) confirmed that the ordinary classroom teacher is unable to provide ass istance for the students with special needs without the help of the shadow teacher, otherwise this requires a high amount of mental and physical effort with a high degree of motivation to carry out this task, which the study described as severe difficulty.

The duties a shadow teacher may be required to fulfill, depending on the childs special educational needs:

1) Provide guidance in completing classroom activities when necessary.

2) Help pupil achieve goals stated in his/her IEP by implementing agreed-upon accommodations.

3) To devise means of adapting the curriculum goals to suit the needs of the child. This may include the need to simplify lessons for the student by preparing appropriate instructional materials.
4) Help student display appropriate classroom behavior.

5) Help student respond appropriately to his/her classmates in social situations (e.g. understand the rules of play and social interaction, sharing and caring).

6) Regularly update the leamer support team on the student's progress. (Lawrence College, 2018).

Although the shadow teacher works autonomously and is not technically a staff member of the school, they are required to comply with all rules and regulations stated in school policies. Furthermore, they are required to maintain discretion and confidentiality of child and family information at all times

\section{The Basic Role of the shadow teacher}

As confirmed by the study of "Maryola, 2009" The shadow teacher has five main and basic roles and they are:

- Cumiculum planning and modification.

- Teaching.

- Modify and manage behavior.

- Social skills management.

- Work as a team

Professional Competences for the shadow teacher

They can be classified into:

1) Lesson planning competencies, including

- Formulation of lesson objectives procedural formulation.

- Formulating lesson objectives in line with the level of experience of the child according to his disability.

- -Determining the appropriate teaching aids for the lesson according to the child's disability and absomtive capacity

2) Competencies of implementing the lesson

- Use the appropriate teaching aids to attract the attention of the child according to the circums tances of his disability.

- Diversification of teaching approaches, methods and strategies according to the nature of the lesson and the nature of the child's disability.

- -Individual educational plan preparation competencies: a set of competencies that make the teacher able to build the educational curriculum for the child, including setting goals, preparing, absorbing and applying the components of the educational plan.

- Educational plan implementation competencies, which are a set of competencies that enable the teacher to implement the individual educational plan, use materials and assistive methods, evaluate and modify behavior .

- Stimulating the child's motivation to leam (Webster,2010).

3) Evaluation/Measurement and Diagnostic Competencies: - Measurement adequacy

- Familiarity with different data collection methods. - The ability to analyze data and identify the strengths and weaknesses of the child 


\section{Diagnostic competencies}

Having a set of educational experiences, which enables the teacher to judge the child based on the measurement information

Competencies of contacting parents

It is the teacher's ability to interact and participate positively with parents and surroundings in order to help the child.

As stated that the shadow teacher to be effective must be:

-Has sufficient knowledge and experience in behavior management or applied behavior analysis.

-Experience working with children with disabilities.

-Ability to encourage or enhance peer relationship and play.

-The ability to deal based on the situation, when to intervene and when to let the child depend on himself.

-The ability to enhance communication with the regular teacher.

-The ability to adapt in the classroom while supervising the child closely (Waters,2012).

Problems that shadow teachers face due to lack of experience and good preparation

By reviewing the literature, it is possible to summarize to:

1. Specific shadow teachers have general knowledge of inclusive education, shadow teachers know that basically, inclusive education is non-discriminatory education; shadow teachers also have knowledge of the objectives, functions, and benefits of inclusive education.

2. Shadow teachers carry out their roles and duties in assisting children with special needs based on the characteristics and abilities of leamers. However, shadow teachers do not cooperate with regular teachers in preparing teaching materials.

3. Coordination of shadow teachers and regular teachers in dealing with students with special needs is lacking. Shadow teachers are not involved in the identification and assessment process. The implementation of a flexible curriculum is not realized, because of the lack of knowledge of shadow teachers about the curiculum that suits the needs of leamers.

From the previous presentation, it is clear to us that the lack of good preparation for the shadow teacher and the attempt to raise his profess ional competencies negatively affect the progress of the educational process in general and the educational integration process in particular.

Accordingly, the researcher is trying to benefit from the TEACCH program in an attempt to raise the professional competencies of the shadow teacher, due to its importance in the process of educational integration, as confirmed by many studies, including (Yuwonom,2017Al-Sabatin,2020 Abdul Hamid, Faiz,2021)

\section{TEACCH program}

(Treatment and Fducation of Autistic and Related Communication Handicapped Children)

It is one of the therapeutic programs that are used with children with autis $m$, and this program was developed by Eric Schopler in 1972, and it is considered the first educational program specialized in teaching autism and people with communication disorders, and it is considered a program approved by the American Autism Association.

This service is provided by TEACCH Centers in the state of North Carolina in the United States of America, where these centers are managed by a specialized center at the University of North Carolina called TEACCH Division, supervised by Professors "Eric Shcopler and Jerry Mesibov", who are senior researchers in the field Autism, where the educational services of this program are provided by teachers and specialists who hold higher degrees in psychology and special education who have extensive experience in teaching children with autism and how to benefit from the Teach program

This program has many advantages in addition to early intervention. It depends on the organized education system or the organization of the child's environment; whether he is at home or school, as this method has proven that it suits the child with autism and suits his world. One of the advantages of this program is that it looks at the child with autism each individually; TEACCH makes special educational programs for each child according to his social, mental, physical and language abilities, and therefore using deliberate tests.

\section{The basis of the TEACCH program}

1) Training and careful organization of the elements of the environment surrounding the child to make him feel safe, and help him pay attention and focus on the elements that are directly related to the work he performs, such as clearing the walls of pictures and drawings, blacking out the windows to reduce visual and auditory distractions as much as possible.

2) 2-Arranging materials and tools to be within the reach of the child so that it is easy to obtain them to perform the target activity and then retum them back to their original place.

3) Using daily activity schedules that include identifying and sequencing the required tasks for each period (Giovanni,2013).

\section{TEACCH Program Objectives}

\section{General goals}

1- Early intervention through the use of constructivist education to encourage communication skills, social skills, playing skills and attention.

2- Training the parents through their participation in designing the child's sessions. The training component requires an indicative "guiding" note, discussion, information gathering, and transfer of 
experiences through cooperation in implementing the activities designed by the teacher (Mesibov\& Victoria, 2009).

\section{Procedural goals}

1. Reducing behavioral problems and developing appropriate social behavior.

2. Teaching cognitive and academic aspects, developing fine motor skills, eye-hand synergy, developing independence skills, and developing expressive and receptive linguistic communication (Schopler \& M. Lansing, 2012).

The most important techniques of the TEACCHStructured Teaching

Is the intervention philosophy that has been developed by the University of North Carolina Department (TEACCH), a systematic approach to the training of individuals with autism, allowing the implementation of a variety of teaching methods as strategies visual support and exchange system through images, (PECS), and strategies for integration of sensory sessions attempts it is one of the systems in dealing with individuals with autism (shaaban,2021)

It is Schopler, the founder of TEACCH, who laid the groundwork for structured education in his Ph.D. thesis by emphasizing the following points:

- That structured education is based on an understanding of the unique features and characteristics associated with the nature of individuals with autism

- Organized education describes the conditions and conditions that an individual must leam.

- Organized education is a system for regulating the environment, developing appropriate activities, and helping individuals with autism understand what is expected of them

- Structured instruction uses visual aids and cues that help autistic people focus on important information as much as possible, as it is sometimes difficult for autistic people to focus on details.

- Organized education believes that all individuals who suffer from autis $m$ have strengths and special interests that can become more functional and can benefit from them later.

- Structured education can be used in classes, homes and workshops for different ages and levels of development, according to the needs of each individual

- The TEACCH program uses structured learning as an attempt to adapt the environment of individuals with autis $m$ to the maximum of their strengths by creating a very high ecosystem to increase the processing problems of these individuals (Shahane $\boldsymbol{k}$ Rubina,2011).

So, organized education is: a set of principles and strategies planned and organized based on a set of activities and healing practices and techniques aimed at the development of communicative, social, independent, professional skills and the skills of daily life for individuals with autism commensurate with the characteristics and culture of autism, one of the most fundamental pillars of the TEACCH program (Elsbah,2017).

The organized learning environment is based on

- Create a specific routine

- Organizing spaces

- Daily visual schedules

- Work organization

- Visual Instructions

The research problem

The research problem can be summarized in the following main question:

What is the Suggested visualization for developing the professional competencies of the shadow teacher in light of the techniques of the TEACCH program?

The main question includes the following sub-questions:

1. What are the professional competencies of the shadow teacher?

2. What are the techniques of the TEACCH program?

3. What is the reason for using the TEACCH program in particular to develop the professional competencies of the shadow teacher?

4. How can the TEACCH program be used to develop the professional competencies of the shadow teacher?

\section{Justifications for the proposed concept}

The importance of the proposed concept stems from the importance of the research problem, which is that: Although the TEACCH program is considered an addition to our Arab society because of its many advantages that put it at the forefront of intervention programs, it is criticized by some specialists, believing that it was better for autistic people to leam and adapt in environments similar to natural environments instead of the virtual leaming environment that gives the TEACCH program Its distinctive character, not all children with autis $m$ need the same degree of organization. Children and adults who have a low degree of intelligence or who are young need the greatest amount of organization. With the advancement of chronological and mental age and language skills, the student's needs for organization gradually decrease, and therefore the it was required to For autis $m$, measuring the extent of the student's needs for such organize by observing his behavior, to reach the lowest possible degree of organization and as close as possible to natural environments. The autistic child needs to leam in a natural environment using the strategies of a successful and effective program such as the TEACCH program

the virtual environment due to the difficulty of applying it in the regular classroom, The presence of the Shadow 
Teacher became necessary on the educational arena and the presence of many studies that It has proven its effectiveness in dealing with the autistic child in particular and children with special needs in general, then The process of applying the program within the regular semester will become possible and we will avoid the only defect in the program because one of the defects of the virtual environment is that when the autistic child comes out The natural world has a feeling of confusion and distraction, so it must live and leam in a natural environment, in addition to the possibility of exploiting the organized leaming environment in training the shadow teacher and raising his professional competence.

So why we don't take advantage of the effectiveness of a program such as TEACCH and its structured leaming environment in teaching children in normal environments with the presence of the shadow teacher, as dealing with the TEACCH program and adhering to the strategies of structured leaming in it will increase the professional competence of the shadow teacher, as one of the features of this program is that it is accurate and detailed, explaining the methods of dealing with each pillar of The pillars of structured education, and there is a special annex that contains 350 activities for each of the problems facing the autistic child. There is also a remedial activity for it, as it is easy to use. The researcher believes that when shadow teachers rely on it, their skills will increase and their profess ional efficiency will improve. with rehabilitation, as they suffer from There are few qualification opportunities, as the qualification of such a category is limited to Cairo University, Faculty of Early Childhood Education, where a new professional diploma has been created that works to rehabilitate them. This diploma is the only diploma in the Arab Republic of Egypt approved by a government agency to prepare this category of teachers. Nonspecialists are hired to take care of this category of children due to the scarcity of trained and qualified shadow teachers.

\section{Methodology:}

The descriptive approach is the appropriate approach for this research, where we reviewed the literature related to the shadow teacher and his competencies and the TEACCH program and its techniques and pillars in an attempt to integrate them and benefit from the program and its effectiveness in treating children with special needs using educational techniques that contribute to raising and developing the professional competencies of the shadow teacher.

\section{Results}

Through the previous presentation, the research questions were answered, which consist in determining the profess ional competencies of the shadow teacher, and clarifying the idea of using the TEACCH program in particular to develop these competencies, By clarifying that the techniques of the TEACCH program which developed by Eric Shcopler at the University of North
Carolina contribute significantly and effectively to the progress and treatment of children with special needs because it is based on precise techniques and depends on an organized leaming environment that facilitates the educational process for children with special needs. The shadow teachers were directed to use the techniques of the TEACCH program in the educational process, which contributes to raising their professional competencies

\section{Recommendation}

1. Demanding the establishment of intemational standards for the professional competencies of the shadow teacher, due to the lack of clear standards.

2. Attention to the preparation and training of shadow teachers within the faculties of education.

3. Creating a new division in the faculties of education to prepare the shadow teacher.

4. Holding training courses as an attempt to raise the professional competencies of shadow teachers.

5. Training shadow teachers to use remedial programs and benefit from them to develop their professional competencies.

\section{Conclusion and further studies}

It is clear from the previous presentation the importance of the shadow teacher in the education and treatment of children with special needs, as it has become one of the basics of the educational integration process. The child is not accepted into the school integration system unless there is a shadow teacher or educational assistance as it is called by Ministerial Resolution No. 42 of 2015. Therefore, the family of the child is responsible for providing it, regardless of his scientific background. The mere presence of a person taking responsibility for the child is sufficient for the school and the educational administration to accept the child and his companions. Hence, the current research came in an attempt to raise the professional competencies of this category of teachers using the therapeutic TEACCH program, which is characterized by looking at each child separately. It sets the individual educational plan that suits each child and his needs using the organized leaming environment that is based on (the use of specific routine - organizing spaces - illustrated daily schedules - organizing work - visual instructions), and the activities that address the daily problems facing a child with special educational needs. Also, this program has proven its effectiveness in treating children with special needs in many aspects of language, movement, social and other, and it is taken for granted that it treats children in virtual leaming environments. - The shadow teacher is the product of educational changes in the field of education and care for children with special needs, because of its positive impact on the success of the educational integration process, as proven by many studies.

\section{can be summarized in the following points}

- The structured leaming environment in the TEACCH program contributes to raising the professional competencies of shadow teachers if they are trained to use the structured leaming environment as part of the daily remedial program, since it includes the basic pillars 
that help shadow teachers to plan, implement, evaluate, communicate and participate with parents, and it is one of the most important professional competencies that must To be available with a shadow teacher.

- The idea of the current research came as an attempt to take advantage of the positive aspects of the TEACCH program in raising the professional competence of the shadow teacher and trying to overcome the negatives of the program by applying it within the real educational environment in the presence of a shadow teacher trained to use the program, and both of them positively affect the treatment and education of children with special needs.

\section{References}

[1] Abdul Hamid \&faiz,zekra.(2021). Role of Shadow Teacher in the provision of Academic and Social Support for Children with Special Needs at Inclusive Schools, Journal of Inclusive Education Vol.4, Is sue 1, 2020, 129-144.

[2] Alhaj, A mira Mazen Mousa.(2017). Shadow Teacher to Supporting Students with mental disabilities, behavioral disorders and comminicationdisorders: Dubai, kindeel, printing, publishing, distribution .

[3] Al-Sabatin, Ibrahim Mahmoud.(2020). The Role of Shadow Teacher in Improving Autistic Students Ability in Learning: Advances in Social Sciences Research Journal - Vol.7, No.9.

[4] Bulter, kathal.(2016).The effectiveness of the TEACCH approach in supporting the development of communication skills for learners with severe intellectual disabilities: NASEN, DOI: 10.1111/14679604.12128.

[5] Butt, R, .(2016) .Employment Procedures and Practices Challenge Teacher Assistants in Mainstream Schools :School Leadership \& Management.(1).p.6379

[6] Cervera ,Sanz\&M Inmaculada Fernández-Andrés .(2018). THE effectiveness of TEACCH intervention in autism spectrem disorder A review study :Universidad de Valencia: Papeles del Psicólogo / Psychologist Papers, Vol. 39(1), pp. 40-50.

[7] Devecchi, P C., Dettori, F., Doveston.(2012). Inclusive classrooms in Italy and England: the role of support teachers and teaching assistants .European Journal of Special Needs Education.(2).p171-184.

[8] Elsbah,soheir. (2017). The effectiveness of using the TEACCH program in developing sensory and perceptual skills for children with autism : International Journal of Educational and Psychological Studies.vol(2).

[9] Giangreco, M\& Edelman, S. (2011). Paraprofessional Support of Students with Disabilities: Literature from the Past Decade Exceptional Children.(1).p 45-63.

[10] Giovanni Valeri, Fabiana Sonnino , Ilaria Fontana.(2013). A Longitudinal Study of the TEACCH Program in Different Settings: The Potential Benefits of Low Intensity Intervention in Preschool Children with Autis m Spectrum Disorder: Journal of Autism and Developmental Disorders. Original paper.

[11] Kamath,Akshata.( 2016). what is the shadow teacher?:Shanghai jornal, p(214-236).

[12] Lestari, Abd. Nasir\& Indah Winarni, Retno.( 2019) .THE Experience of shadow teacherin helping children with special needs in telgo patut elementary school: I GRESIK .Ilmu Keperawatan.

[13] Machrus ,Muhammad Ali.(2019). Strong Motivation be My Success in Teaching :How A Teacher Handling Hyperactive Student in Inclusive School with Eliminate the Shadow Teacher: International Journal of Humanities, Arts and Social Sciences.(5).

[14] Manasala ,Maryola \& Dizon, A. Edilberto I.( 2009). Shadow Teaching Scheme for Children with Autism and Attention Deficit-Hyperactivity Disorder in Regular Schools:Education Quarterly-p.43-49.

[15] McConkey, R \&Dobbins, M Abbott. L.(2011) .Key players in inclusion: are we meeting the professional needs of learning support assistants for pupils with complex needs?: European Journal of Special Needs Education (2).p215- Broer, S 231.

[16] Mesibov, Gary B. ,Victoria Shea.(2009). The TEACCH Program in the Era of Evidence-Based Practice: Journal of Autism and Developmental Disorders. Original paper.

[17] Nesma,shaaban.( 2021). The effectiveness of a training program based on TEACCH in developing visual perception among autistic children: Journal of the Faculty of Education, Damietta University,jul.(78).

[18] Shahane ,Anagha \& Rubina, Lal.(2011 . )TEACCH Intervention for Autism .India: Department of Special Education, SNDT Women's University, Mumbai.

[19] St. Lawrence College,(2018). Junior School Special Educational Needs and Disability Policy, the British School in Greece.

[20] Waters, L\& E. Schopler \& M. Lansing .(2012). Activités d'enseignement pour enfants autistes: Masson Ed.

[21] Webster, Bassett P \& R., Blatchford .(2010 . Double standards and first principles: framing teaching assistant support for pupils with special educational needs :European Journal of Special Needs Education.(4).p319-336.

[22] Yuwono, Imam \& Uto mo, Agus Pratomo.(2017). Shadow Teacher Social Interaction Problem in SDN of Gadang 2 Banjarmasin: Advances in Social Science, Education and Humanities Research (ASSEHR), volume 147- "Multicultural Transformation in Education, Social Sciences and Wetland Environment" (ICSSE 2017).

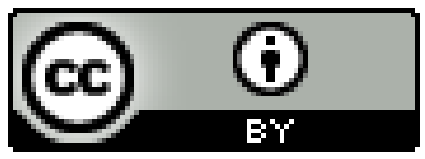

